\title{
A relação Estado-Igreja e o papel da religião nas relações internacionais da Rússia ${ }^{1}$
}

The Church-State relations and the role of religion in Russia's international relations

La relación Estado-Iglesia y el papel de la religión en las relaciones internacionales de Rusia

Luiz Felipe Dias Pereira ${ }^{2}$

DOI: 10.5752/P.1809-6182.2019v13n3p15

Recebido em: 13 de maio de 2019 Aceito em: 26 de agosto de 2019

\begin{abstract}
Resumo
$O$ artigo aborda a relação Estado-Igreja existente na sociedade russa. Argumenta-se que a religiäo náo deve ser ignorada ao se analisar as politicas doméstica e externa da Rússia contemporânea. $O$ argumento tem como base revisão bibliográfica sobre o tópico e informaçóes obtidas no website do Department for External Church Relations.
\end{abstract}

Palavras-chave: Relaçôes Internacionais. Rússia. Religiāo. Igreja Ortodoxa.

\begin{abstract}
This article concerns the State-Church relationship in the Russian society. The argument is that religion should not be neglected when analysing contemporary foreign and domestic politics. The author's argument is based on bibliographical review about the subject and information obtained on the Department for External Church Relations' website.

Keywords: International Relations. Russia. Religion. Orthodox Church.

\section{Resumen}

El artículo aborda la relación estado-iglesia existente en la sociedad rusa. Se argumenta que la religión no debe ser ignorada cuando se analizan las políticas internas y externas de la Rusia contemporánea. El argumento se basa en una revisión de la literatura del tema y la información obtenida del sitio web del Department for External Church Relations.

Palabras clave: Relaciones Internacionales. Rusia. Religión. Iglesia Ortodoxa.
\end{abstract}

\footnotetext{
$1 \mathrm{O}$ presente trabalho foi realizado com apoio da Coordenação de Aperfeiçoamento de Pessoal de Nível Superior - Brasil (CAPES)

- Código de Financiamento 001.

2 Mestrando em Relaçôes Internacionais pelo Programa de Pós-Graduação em Relaçôes Internacionais da Pontifícia Universidade Católica de Minas Gerais (PPGRI/PUC Minas). Bacharel em Relaçôes Internacionais pela Pontifícia Universidade Católica de Minas Gerais (PUC Minas). E-mail: luizfdpereira@gmail.com. Belo Horizonte (MG)/Brasil. ORCID: https://orcid.org/00000001-5135-104
} 


\section{Introdução}

A Igreja Ortodoxa Russa - ou o Patriarcado de Moscou - é uma instituição de grande relevância política que atua na sociedade russa em níveis doméstico e internacional. Essa tradição de articulação política com outras igrejas ortodoxas pode ser observada a partir do pan-eslavismo e o uso da religiáo como instrumento geopolítico em naçóes regionais - principalmente no contexto dos Bálcãs ainda sob controle do Império Otomano (GERD, 2014). A ideia de Moscou como a Terceira Roma ${ }^{3}$ existe desde a queda do Império Bizantino; contudo, é a partir do século IXX que a Rússia busca se consolidar como protetora do cristianismo ortodoxo no mundo (KLIMENKO; YURTAEV, 2018).

Este estudo parte da seguinte questão: qual é a influência da proximidade entre Estado e Igreja para a política externa russa contemporânea? $\mathrm{O}$ autor deste trabalho sugere que o uso da religião enquanto instrumento de política externa se trata de um fenômeno que pode ser melhor compreendido a partir de um estudo sobre o posicionamento da Rússia enquanto protetora do cristianismo ortodoxo na sociedade internacional. Nesse sentido, é possível observar que o papel político ativo da Igreja Cristá Ortodoxa Russa no país se trata de um elemento que não deve ser ignorado em debates sobre política externa e geopolítica da Rússia.

Buscar-se-á, aqui, realizar uma contextualização histórica no que diz respeito à consolidaçáo da religiáo cristã ortodoxa enquanto instituição politicamente ativa, além da proximidade entre Igreja e Estado.

3 A Segunda Roma seria Constantinopla, capital do Império Bizantino.
Nesse sentido, é importante levar em conta a influência da Igreja na política externa russa no período pós-soviético. Ademais, propõe-se uma breve análise da atuação política da Igreja na contemporaneidade, demonstrando, por exemplo, a articulaçáo do Patriarcado de Moscou com os demais patriarcados europeus, de forma geral. No fim, o autor argumenta que a relação entre Estado e Igreja na Rússia pode representar uma contribuição no tocante à questão dos estudos sobre religiáo no campo das R.I..

\section{O Cristianismo Ortodoxo na Rússia}

A fins de contextualização, serão apresentados, nesta seção, um breve histórico da presença do cristianismo ortodoxo na Rússia, de modo a prover ao leitor uma melhor compreensão do papel da Igreja Ortodoxa Russa (daqui em diante, abreviada como IOR) enquanto ator político na sociedade.

O conceito de symphonia $a^{4}$ data desde o Império Bizantino para definir a relação entre Igreja e Estado, afirmando a ideia de que "as autoridades políticas e religiosas devem trabalhar juntas em um acordo sinfônico de modo a alcançar o bem estar material e espiritual dos fiéis" (LEUSTEAN, 2011, p.188, tradução nossa) $)^{5}$. O termo symphonia representa uma "correlação harmoniosa interdependente entre o Estado e autoridades eclesiásticas" (PROSIC, 2014, p.180, tradução nossa $)^{6}$. As duas esferas seriam interdependentes no que diz respeito ao

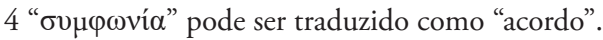

5 Political authorities should work together in a symphonic agreement towards achieving the material and spiritual welfare of the faithful.

6 Harmonious interdependent correlation between state and ecclesiastical authorities.
} 
que o autor denomina como uma emanação do divino, isto é, um "objetivo final para ambos o imperador e a igreja" (PROSIC, 2014, p. 180, tradução nossa) ${ }^{7}$. Nesse sentido, as duas instituiçôes atuariam de modo a "administrar diferentes necessidades", porém, ambas as instituiçóes poderiam ser vistas como sendo unânimes, uma vez que as duas compartilhavam de uma mesma origem (PROSIC, 2014, p.182, traduçáo nossa). ${ }^{8}$ Uma vez apresentado o conceito, a próxima seção irá abordar o contexto histórico da relação entre Estado e Igreja na Rússia.

\section{Estado e religiõo na Rússia}

A presença do cristianismo ortodoxo na sociedade russa não é recente. Sabe-se que o primeiro Estado de povos eslavos teve origem em Kiev, capital da atual Ucrânia, sendo o Estado de Kiev viria a adotar o cristianismo ortodoxo como religiáo oficial russa, juntamente com o alfabeto cirílico, que deu origem à língua russa em sua forma escrita (ZIEGLER, 2009). A proximidade entre Estado e Igreja tem origem nos primórdios da formação do governo de Kiev e da sociedade russa. Essa relaçấo é descrita por Ziegler (2009) como tendo caráter simbiótico, levando em conta que o cristianismo ortodoxo foi o alicerce da uniâo cultural que ligava os principados descentralizados de Kiev.

Em um primeiro momento, Estado e Igreja atuaram em harmonia, de modo que esta agia como "a consciência moral e apoiadora do Estado", sendo que essa relação teria fim no início do século XVIII, com a subordinação da Igreja ao Estado estabelecida por Pedro, o Grande (PETRO apud ZIEGLER,

7 Ultimate goal of both the emperor and the church. 8 Administer to different needs. p.13, tradução nossa) ${ }^{9}$. Levando em conta a proximidade entre Estado e Igreja na Rússia, é imprescindível mencionar o movimento do pan-eslavismo, considerando sua importância para a política externa russa.

\section{A Terceira Roma}

Durante os séculos XIX e XX, o principal objetivo da política externa russa no Oriente Próximo consistiu na busca por uma "união do mundo Ortodoxo sob a Rússia”, sendo que essa concepção política neobizantina tem origem na ideia de que Moscou seria considerada como a Terceira Roma (GERD, 2014, p.20, traduçâo nossa) ${ }^{10}$. Esse conceito remete ao casamento de Ivan III com a sobrinha do último imperador bizantino (Constantino XI Paleólogo), Sofia Paleóloga. O matrimônio celebrou a transferência da herança real bizantina para Moscou e, após 1480, Ivan III adota o título de tsar, fato que celebrou tanto o fim do domínio Mongol sobre a Rússia, quanto a apropriação do legado bizantino (SHUBIN, 2004). A ideia de Moscou como a Terceira Roma passou a significar para a Rússia a restauração do Império Bizantino, sendo que o país passou a desejar que sua capital fosse o centro desse mundo (GERD, 2014). A Rússia seria, posteriormente, vista por cristãos ortodoxos como uma salvação da dominação Otomana (GERD, 2014).

É importante compreender o paneslavismo para se entender a atuação da IOR na política internacional na contemporaneidade. Não menos importante foi a mudança na relação entre Estado e Igreja durante o período soviético. A hostilidade em relação à religião se manifestou logo após chegada dos bolcheviques

9 The moral conscience and supporter of the state. 10 Union of the Orthodox world under Russia 
ao poder. Em 1928 foi estabelecido o Decreto sobre a Separação de Igreja e Estado que, além de estabelecer a separação entre as instituições no sistema educacional, também retirou das igrejas o direito de possuir propriedades e seus direitos de entidade legal (WALTERS, 1986).

A ideia da Rússia como Terceira Roma foi abandonada durante esse período, uma vez que a União Soviética agora tinha como objetivo "construir o novo sistema de relaçóes internacionais com base na justiça e na paz" (KLIMENKO; YURTAEV, 2018, p. 242, tradução nossa $)^{11}$. Houve também, além do abandono da tradição geopolítica russa, um movimento ideológico voltado para o ateísmo que contribuiu para uma deformação do conceito de Terceira Roma (KLIMENKO; YURTAEV, 2018).

\section{A ressurgência da Igreja e da religião na Rússia}

Lamoreaux e Flake (2018) afirmam que a IOR teve sucesso no que se refere ao seu "restabelecimento como religião dominante na Rússia, frequentemente por meio do apoio da legislaçáo" (LAMOREAUX; FLAKE, 2018, p.2, tradução nossa $)^{12}$. No início da década de 1990 , a Igreja recebeu de volta as terras que haviam sido apreendidas pelo Estado e, não obstante, a lei de Liberdade de Consciência e Associação Religiosa de 1997 "permitiu uma alavancagem implícita para a Igreja ao limitar o que outras organizaçóes religiosas poderiam fazer" (LAMOREAUX; FLAKE, 2018, p.2, tradução nossa) ${ }^{13}$.

11 To build the new system of international relations on the basis of justice and peace.

12 Re-establishing itself as the dominant religion in Russia, often through state supported legislation.

13 Provided implicit leverage to the Church by limiting what other religious organisations could do.
Além disso, dentre as principais mudanças que ilustram a consolidação da IOR como principal ator religioso na Rússia, pode-se citar três que foram feitas já no período de Kirill ${ }^{14}$ como Patriarca: o fortalecimento da reivindicação da Igreja sobre terras tomadas no período soviético, uma diretiva que permite o ensino religioso em escolas públicas e a terceira diz respeito aos benefícios relativos a impostos, como "tax breaks" e propriedade parcial sobre firmas de energia (KISHKOVSKY apud LAMOREAUX; FLAKE, 2018; KÖLLNER apud LAMOREAUX; FLAKE, 2018; SOLODOVNIK apud LAMOREAUX; FLAKE, 2018). Ademais, no contexto de uma sociedade pós-soviética, a IOR, visando à sua renovação e desenvolvimento, ignorou o passado da secularização soviética ${ }^{15}$, assumindo novamente sua posição na sociedade tendo como modelo a época em que a mesma não era separada do Estado (ZORKAIA, 2014).

\section{ОТДЕЛ ВНЕШНИХ ЦЕРКОВНЫХ СВЯЗЕЙ/Department of External Church Relations}

De acordo com Blitt (2011), "o Patriarcado de Moscou, assim como o governo russo, é ativamente preocupado em relação a desenvolvimentos fora da Rússia e as potenciais implicaçôes que esses desenvolvimentos possam ter no ambiente doméstico" (BLITT, 2011, p. 365, tradução nossa) ${ }^{16}$, sendo que essa preocupação

14 Patriarca de Moscou desde 2009.

15 Entende-se por secularizaçáo, aqui, o processo que diz respeito à diminuiçấo da importância da religião no cotidiano em determinada sociedade. Para maiores detalhes, ver: Rethinking Secularism, de: CALHOUN, Craig Jackson; JUERGENSMEYER, Mark; VanAntwerpen.

16 The Moscow Patriarchate, like the Russian government, is actively concerned about developments outside of Russia and the potential implications these developments may have on the home front. 
se refere náo somente aos Estados da antiga União Soviética, mas também por todos os Estados nos quais cristãos ortodoxos estejam sujeitos à sua jurisdição (BLITT, 2011). O principal que, segundo Blitt (2011), atua como um ministério estrangeiro e interage instrumento da IOR no que se refere a questóes de assuntos estrangeiros/internacionais é o Departamento de Relações Exteriores da Igreja (Department for External Church Relations, ou DECR) com instituiçóes internacionais como a Organização das Naçôes Unidas e a União Europeia.

Levando em conta a proposta deste trabalho, é digno de menção o website do DECR, que pode ser utilizado como fonte de documentos que permitem observar o funcionamento da instituição. Disponível em seis idiomas, o site - online desde 1997 - disponibiliza informaçóes desde a biografia do atual patriarca Kirill no que se refere à sua vida política como presidente do DECR, de 1989 a 2009 (DECR, 1997-2019a) - assim como textos de discursos como, por exemplo, discursos do patriarca Kirill em encontros com o presidente Putin (DECR, 2017). No endereço, também é possível encontrar informaçóes sobre relaçôes "interortodoxas", "inter-cristâs" e "inter-religiosas" da instituição.

De acordo com o próprio site da instituição, o DECR do Patriarcado de Moscou é "uma grande instituição sinodal da Igreja Ortodoxa Russa” (DECR, 1997-2019b, tradução nossa). ${ }^{17}$ No que se refere às suas funções, o DECR

\begin{abstract}
Mantém as relaçóes da Igreja Ortodoxa Russa com Igrejas Ortodoxas Locais, Igrejas não-ortodoxas, associaçóes cristãs e comunidades religiosas não-cristãs, assim como instituiçóes governamentais, parlamentares, inter-gover-
\end{abstract}

17 A major Synodal institution of the Russian Orthodox Church. namentais, religiosas e públicas no exterior e organizações internacionais públicas (DECR, 1997-2019c, tradução nossa). ${ }^{18}$

Nota-se que os assuntos externos da IOR não se limitam apenas ao contato com outras Igrejas Ortodoxas. Não obstante, também é atividade do DECR "informar o Patriarca e o Santo Sínodo sobre eventos e atividades fora da Igreja Ortodoxa Russa envolvendo seus interesses", além da produção de documentos e decisóes no que se refere questóes de natureza "inter-ortodoxa, inter-cristãs, interreligiosas e internacionais" (DECR, 1997-2019b, tradução nossa). ${ }^{19} \mathrm{O}$ estatuto da IOR foi adotado em 2000, e emendas baseadas nos Conselhos de Bispos foram adotadas posteriormente. $\mathrm{Na}$ primeira seção do estatuto, referente às disposiçóes gerais, a IOR é definida como "uma igreja multinacional local autocéfala em unidade doutrinal em comunhão orante e canônica com outras Igrejas Ortodoxas Locais" (DECR, 1997-2019c, tradução nossa). ${ }^{20}$

Também é importante mencionar os textos disponíveis no site do DECR no que concerne à seção sobre conceitos sociais, mais especificamente o tópico sobre as delimitaçôes nas relaçôes entre Estado e Igreja. De acordo com o site, "as áreas de cooperação entre Estado e Igreja no período histórico presente" envolvem assuntos como "peacemaking nos níveis internacional, inter-étnico e cívico, e

18 Maintains the Russian Orthodox Church's relations with the Local Orthodox Churches, non-Orthodox Churches, Christian associations, non-Christian religious communities, as well as governmental, parliamentary, non-governmental institutions abroad and inter-governmental, religious and public international organizations.

19 Inter-Orthodox relations; inter-Christian relations;interreligious relations

20 a multinational Local Autocephalous Church in doctrinal unity and in prayerful and canonical communion with other Local Orthodox Churches. 
promoção mútua da compreensão e da cooperação entre povos, naçôes e Estados"; "diálogo com órgãos governamentais de todas as ramificaçôes e níveis em questôes importantes para a Igreja e a sociedade, incluindo o desenvolvimento de leis, estatutos, instruçôes e decisôes"; "trabalho da mídia de massa eclesiástica e secular"; entre outros (DECR, 1997-2019d, tradução nossa). ${ }^{21}$

Nesse sentido, pode-se dizer que influência da Igreja sobre as relaçóes internacionais da Rússia se torna relevante na medida em que a IOR "cresceu como uma força capaz de gerar ideias e fazer lobby a favor de certos rumos da política externa russa” (LOMAGIN, 2012, p.7, tradução nossa ${ }^{22}$. A IOR também exerce influência nas esferas social, econômica e educacional, provendo uma base para a constituição de um aumento de influência política e adquirindo a capacidade de legitimar algumas das políticas do Kremilin (LOMAGIN, 2012). Para Lomagin (2012), a IOR teve êxito no que concerne à restauração de seu poder nas últimas décadas. A relação entre Estado e Igreja na Rússia contemporânea é caracterizada pelo compartilhamento de uma ideologia nacionalista por ambas as instituiçôes, visando à "restauração do poder russo após a desorganização que seguiu o fim da Uniāo Soviética” (LOMAGIN, 2012, p.14, tradução nossa) ${ }^{23}$.

21 The areas of church-state co-operation in the present historical period; peacemaking on international, inter-ethnic and civic levels and promoting mutual understanding and co-operation among people, nations and states; dialogue with governmental bodies of all branches and levels on issues important for the Church and society, including the development of appropriate laws, by-laws, instructions and decisions; work of ecclesiastical and secular mass media;

22 Grown as a force, which was capable of generating ideas and lobbying in favour of certain directions of Russian foreign policy.

23 Restoring Russia's might after the disarray that followed the end of the Soviet Union
Além disso, observa-se que a instituição declara que sua jurisdição se estende a pessoas de fé ortodoxa nos territórios classificados como canônicos, fazendo referência aos territórios de diversos países, como as ex-repúblicas soviéticas, assim como China e Japão (DECR, 1997-2019e). Com base nessa declaração, é possível associar o discurso relativo à jurisdição do Patriarcado de Moscou com a projeção da Rússia enquanto protetora dos cristãos ortodoxos para além do território russo, ideia compartilhada por grande parte da população de países do leste europeu e/ou das ex-repúblicas soviéticas.

$\mathrm{Na}$ contemporaneidade ${ }^{24}$, a IOR assume um papel diferente daquele assumido durante o período soviético; no que concerne à política externa da Rússia pós-soviética, Lomagin (2012) afirma que a instituição participou de "projetos de integração no território da antiga União Soviética" (LOMAGIN, 2012, p.2, tradução nossa) ${ }^{25}$. Com essa mudança, a IOR se projeta de forma mais ativa no âmbito internacional, articulando politicamente com instituiçôes internacionais como a Organização das Naçóes Unidas e a União Europeia (LOMAGIN, 2012).

Como demonstrado previamente, a Igreja Ortodoxa sempre esteve presente nos contextos políticos (doméstico e externo) russos. Mesmo durante o período soviético, a tradição de uma Igreja sujeita à autoridade do Estado (que data desde o governo de Pedro, o Grande)

24 Devido ao escopo desta pesquisa, optou-se pela utilização dos termos "contemporaneidade" (termo utilizado por Lomagin (2012) em seu artigo para se referir à Rússia após o fim da URSS e a partir dos anos 1990 - e "pós-soviético" como o contexto social russo desde o fim da União Soviética até o momento no qual este artigo foi escrito.

25 Integration projects on the territory of the former Soviet Union. 
foi mantida, de modo que o próprio governo soviético havia utilizado a Igreja como instrumento de política externa (HERPEN, 2016). Já na primeira década do século XXI, a IOR "trabalhou duro para aperfeiçoar seu relacionamento com as primeiras administraçôes de Putin (2000-2008)" (ANDERSON, 2016, p.15, tradução nossa $)^{26}$.

A cooperação entre Estado e Igreja adquire "um novo patamar" sob o governo Vladimir Putin, razão pela qual Herpen (2016) define a Igreja como "um instrumento de soft power ${ }^{27}$ da política externa do Kremilin" (HERPEN, 2016, p.132, tradução nossa). ${ }^{28}$ Putin assumiu publicamente sua fé no cristianismo ortodoxo em 1993, sendo que seu mandato como primeiro ministro e subsequentemente presidente em exercício em 1999 seria marcado por uma concatenação de motivaçóes pessoais e políticas. A respeito dessas motivações, Herpen (2016) comenta que

Deste ponto, para o novo líder do Kremlin a aliança com a igreja também era ditada pela raison d'état, e isso por duas razóes. A primeira razáo foi que, quando ele acedeu ao poder supremo do Estado, Putin instintivamente seguiu a prescrição de Maquiavel de que era útil para um governante se comportar como se ele fosse religioso, sem ser necessariamente religioso. A segunda razão foi que ele entendeu muito bem o papel útil que Igreja Ortodoxa Russa poderia desempenhar na

26 Worked hard to perfect its relationship with the first Putin administrations (2000-2008).

27 Entende-se soft power como "A habilidade de conseguir o que você quer por meio da atração em vez da coerção ou pagamento. Surge da atratividade da cultura de um país, ideais políticos e políticas" (NYE, 2004, p.10, tradução nossa). No original: "It is the ability to get what you want through attraction rather than coercion or payments. It arises from attractiveness of a country's culture, political ideals and policies."

28 A new high; a "soft-power" tool of the Kremlin's foreign policy. reconstrução do império perdido (HERPEN, 2016, p.134, traduçáo nossa). ${ }^{29}$

Anderson (2016) argumenta que, a despeito de a Rússia ser, constitucionalmente, um país secular, politicamente, a relação entre a IOR e Putin faz com que o país não se caracterize como tal, uma vez que a IOR se tornou parte da coalizão conservadora de apoio construída pelo próprio presidente. A IOR desempenha o papel de igreja dominante no país, e Putin já chegou a afirmar que "a ortodoxia é um elemento central da identidade civilizacional da Rússia” (ANDERSON, 2016, p. 4, tradução nossa). ${ }^{30}$

Desta forma, pode-se afirmar que Putin incorporou a religião à política externa, considerando a importância de indivíduos falantes da língua russa no exterior (DEMYDOVA, 2019). Ainda no que diz respeito à política externa russa, Demydova (2019) o grupo de trabalho do Ministério Russo das Relaçóes Exteriores e a Igreja Ortodoxa Russa, que existe desde 2003 e se reúne anualmente para discutir questôes relevantes da política externa da Rússia. Vale mencionar também que a IOR participa ativamente na formulação de políticas do Kremlin; na política externa, a IOR também influencia em questôes relacionadas à educação, à cultura e à política (DEMYDOVA, 2019).

Por fim, sugere-se algumas observaçóes. Em primeiro lugar, é possível notar que, ao

29 From this point, for the new Kremlin leader the alliance with the church was also dictated by the raison d'état, and this for two reasons. The first reason was that when he acceded to the supreme power of the state, Putin instinctively followed Machiavelli's precept that it was useful for a ruler to behave as if he were religious without necessarily being religious. The second reason was that he understood full well the useful role the Russian Orthodox Church could play in the reconstitution of the lost empire.

30 A core element of Russia's civilizational identity. 
longo da história russa, Estado e Igreja sempre estiveram próximos (HERPEN, 2016). A religião esteve arraigada na cultura russa, sendo um elemento constituidor da identidade russa, como afirmado por Putin (ANDERSON, 2016). Nesse sentido, o cristianismo ortodoxo esteve presente tanto na política doméstica quanto na externa, sendo possível observar uma interseção entre tópicos como religião, política externa (pan-eslavismo) e o modelo de relação entre Estado e Igreja na Rússia; a IOR, como ator internacional, ainda busca exercer influência sobre ex repúblicas soviéticas, sendo uma expressão dessa atuação a ideia de uma suposta extensão da jurisdição do Patriarcado de Moscou sobre outros países (DECR, 1997-2019e).

A relevância da religiáo para a sociedade russa não apenas foi reconhecida por Putin, como também foi utilizada pelo presidente na contemporaneidade como um instrumento de exercício do soft power. A proximidade entre Estado e Igreja na Rússia acaba implicando em políticas que não se configuram como estritamente seculares, considerando que a IOR possui privilégios em relação a outras instituiçôes religiosas no país, ao mesmo tempo em que demonstra apoio ao governo Putin (ANDERSON, 2016). Percebe-se que um estudo histórico que leve em conta o conceito de symphonia pode colaborar para estudos sobre a Rússia contemporânea.

\section{Conclusões}

Buscou-se, neste trabalho, abordar a relação entre Estado e Igreja na sociedade russa, desde a adoção do cristianismo ortodoxo na Kievan Rus, até a ressurgência da Igreja Ortodoxa Russa na contemporaneidade, de modo a demonstrar sua atuação como ator político de relevância em nível internacional. A seguir, pretende-se argumentar sobre possíveis colaboraçôes deste estudo.

Diferentemente do contexto religioso ocidental, no qual houve uma separação entre religião e política, estas estiveram sempre interligadas na sociedade russa (HERPEN, 2016). Essa diferença pode apresentar implicaçôes para os estudos do campo das Relaçôes Internacionais. Levando em conta a origem ocidental do campo das R.I. - cuja origem se encontra relaciona$\mathrm{da}$ ao pensamento Iluminista e à ideia de um Estado secular - i.e., a não interferência da religião na política. Prasad (2014) afirma que uma vez que a disciplina tem raízes na experiência secular europeia ocidental, a religião se encontrou à margem dos estudos do campo.

Feitas essas consideraçóes, o autor deste artigo sugere que o caso abordado apresenta duas implicaçóes. Em primeiro lugar, ao se observar a sociedade russa por meio de uma perspectiva baseada nos termos políticos seculares existentes nos países ocidentais, seria de se esperar que a religião não fosse incorporada em análises políticas da Rússia. Todavia, o presente estudo buscou demonstrar como a religiáo se apresenta como uma variável que não deveria ser ignorada em estudos sobre as relaçóes internacionais da Rússia.

Com base no argumento de Prasad (2014), que estudos sobre contextos tais como a relaçáo de symphonia entre Estado e Igreja na Rússia, que diferem da ideia ocidental de secularismo intrínseco ao Estado moderno referido no campo das R.I., também requerem uma reflexão acerca do entendimento que se tem sobre o secularismo do campo. Nesse sentido, ao se estudar casos similares, é necessária uma análise que se diferencie do entendimento que se tem sobre a natureza da política internacional no Ocidente. Além disso, uma revisão histórica permite a acadêmicos compreender a relação 
Estado-Igreja a partir de uma análise da herança bizantina da Rússia cristã ortodoxa e como isso pode apresentar repercussóes sobre o comportamento de líderes políticos até os dias de hoje.

\section{Referências}

ANDERSON, John. Religion, state and 'sovereign democracy' in Putin's Russia. Journal of Religious and Political Practice, v. 2, n. 2, p. 249-266, 1 jul. 2016. Disponível em: $<$ https://research-repository.st-andrews.ac.uk/bitstream/handle/10023/12406/Anderson_2016_ReligionState_JRPP_AAM. pdf?sequence= 1 \&isAllowed $=y>$. Acesso em: 20 ago. 2019 .

BLITT, Robert C. Russia's 'Orthodox' Foreign Policy: The Growing Influence of the Russian Orthodox Church in Shaping Russia’s Policies Abroad. SSRN Electronic Journal, v. 33, issue 2, winter 2011. Disponível em: <https://scholarship.law. upenn.edu/jil/vol33/iss2/2/ >. Acesso em: 20 ago. 2019.

DEMYDOVA, V. Independence of the Ukrainian Church: How Russia is Losing its Soft Power Tool in Ukraine. Akademik Hassasiyetler, v. 6, p. 251-274, 2019.

DEPARTMENT FOR EXTERNAL CHURCH RELATIONS. Background. In: DEPARTMENT FOR EXTERNAL CHURCH RELATIONS. The Russian Orthodox Church. 1997-2019b. Disponível em: <https://mospat.ru/en/ department/history/> Acesso em: 20 ago. 2019.

DEPARTMENT FOR EXTERNAL CHURCH RELATIONS. DECR today. In: DEPARTMENT FOR EXTERNAL CHURCH RELATIONS. The Russian Orthodox Church. 1997-2019c. Disponível em <https://mospat.ru/en/ department/today/>. Acesso em: 20 ago. 2019.

DEPARTMENT FOR EXTERNAL CHURCH RELATIONS. I. General provisions. In: DEPARTMENT FOR EXTERNAL CHURCH RELATIONS. The Russian Orthodox Church. 1997-2019e. Disponível em <https://mospat.ru/en/ documents/ustav/i/>. Acesso em: 20 ago. 2019.

DEPARTMENT FOR EXTERNAL CHURCH RELATIONS. III. Church and State. In: DEPARTMENT FOR EXTERNAL CHURCH RELATIONS. The Russian Orthodox Church. 1997-2019d. Disponível em <https://mospat.ru/ en/documents/social-concepts/iii/>. Acesso em: 20 ago. 2019.

DEPARTMENT FOR EXTERNAL CHURCH RELATIONS. Speech by His Holiness Patriarch Kirill at the Meeting of the President of Russia Vladimir Vladimirovich Putin with the Participants of the Episcopal Council of the Russian Orthodox Church. . In: DEPARTMENT FOR EXTERNAL CHURCH RELATIONS. The Russian Orthodox Church. 2017. Disponível em: <https://mospat.ru/en/2017/12/01/ news153711/>. Acesso em: 20 ago. 2019.

DEPARTMENT FOR EXTERNAL CHURCH RELATIONS. The Patriarch. In: DEPARTMENT FOR EXTER-
NAL CHURCH RELATIONS. The Russian Orthodox Church. 1997-2019a. Disponível em: <https://mospat.ru/en/ the_patriarch/> Acesso em: 20 ago 2019.

GERD, Lora. Russian Policy in the Orthodox East: The Patriarchate of Constantinople. Warsaw/Berlin: De Gruyter Open, 2014.

HERPEN, Marcel H. van. Putin's propaganda machine: soft power and Russian foreign policy. Lanham: Rowman \& Littlefield, 2016.

KLIMENKO, Anna N; YURTAEV, Vladimir I. The "Moscow as the Third Rome" Concept: Its Nature and Interpretations since the 19 th to Early 21 st Centuries. Geopolíticas, v. 9, n. 2, p. 231-251, 2018. Disponível em: <https://revistas.ucm.es/index.php/GEOP/article/download/58910/4564456548696>. Acesso em: 10 out 2019.

LAMOREAUX, Jeremy W; FLAKE, Lincoln. The Russian Orthodox Church, the Kremlin, and religious (il)liberalism in Russia. Palgrave Communications, v; 4, n. 115, p.1-4, 2018. Disponível em; <https://www.nature.com/articles/s41599018-0169-6>. Acesso em: 11 out. 2019.

LEUSTEAN, L. N. The concept of symphoniain contemporary European Orthodoxy. International Journal for the Study of the Christian Church, v. 11, n. 2-3, p. 188-202, 2011.

LOMAGIN, Nikita. Interest groups in Russian foreign policy: The invisible hand of the Russian Orthodox Church. International Politics, v. 49, n. 4, p. 1-19, jul. 2012.

NYE, JOSEPH S. JR. Soft Power: the Means to Success in World Politics. Nova York, Public Affairs, 208 p., 2004.

PRASAD, Shubha Kamala. The Marginalisation of Religion in International Relations. South Asian Survey, v. 21, n. 1-2, p. 35-50, 2014.

PROSIC, T. Between support for the state and its betrayal: the contradictions of the Eastern Orthodox Christian concept of symphonia. Political Theology, v. 15, n. 2, p. 175-187, 2014. Disponível em: <https://doi.org/10.1179/1462317X1 3Z.00000000073>. Acesso em: 20 ago. 2019.

SHUBIN, Daniel H. The History of Russian Christianity: From the Earliest Years Through Tsar Ivan IV. [S. 1.]: Paperback, v. 1, 240 p. 2004.

WALTERS, P. The Russian Orthodox Church and the Soviet State. American Academy of Political and Social Science, v. 483, n. 1, p.135-145, 1986. Disponível em: < https://www. jstor.org/stable/1045546?seq=1\#page_scan_tab_contents> Acesso em: 20 ago. 2019.

ZIEGLER, Charles E. The history of Russia. Westport: Greenwood Press, oct. 2009. Disponível em: <http://works. bepress.com/charles-ziegler/2/>. Acesso em: 20 ago. 2019.

ZORKAIA, Natalia. Orthodox Christianity in Post-Soviet Society. Russian Politics \& Law, v. 52, issue 3, p. 7-37, 2014. Disponívelem:<https://www.tandfonline.com/doi/citedby/10.2753/ RUP1061-1940520301? scroll=top\&needAccess $=$ true $>$. Acesso em: 20 ago. 2019. 